training and sports in Ukraine, vol.2. Rivne, pp. 371374. [in Ukrainian].

11. Sushchenko, A. V. (2011). Rozvytok pedahohichnoi tvorchosti maibutnikh uchyteliv fizychnoho vykhovannia $\mathrm{v}$ khodi pedahohichnoi praktyky [The development of pedagogical creativity of future physical education teachers during teaching practice]. Pedagogy of formation of creative personality in higher and secondary schools. Zaporozhye, Vol.19. pp. 275-280. [in Ukrainian].

12. Tymoshenko, O. V. (2008). Optymizatsiia profesiinoi pidhotovky maibutnikh vchyteliv fizychnoi kultury: monohrafiia [Optimization of professional preparation of future teachers of physical culture: monograph.]. Kyiv: NPU im. M. P. Dragomanov, 422 p. [in Ukrainian].

Стаття надійшла до редакції 15.02.2018
УДК 378.146:004.4

DOI:

Юлія Корницька, кандидат педагогічних наук, доиент Національний технічний університет Украӥни “Київський політехнічний інститут імені Ігоря Сікорського"

\title{
РОЛЬ ТА МІСЦЕ ТЕСТУВАННЯ В НАВЧАННІ ІНОЗЕМНИХ МОВ
}

У статті розглядається потенціал тестування для організації об'єктивного та технологічного моніторингу якості іншомовної підготовки майбутніх фахівців технічного профілю. На основі теоретичного аналізу актуальних досліджень представлено узагальнений перелік переваг використання тестів та комп'ютерних тестів зокрема, визначено доиільність використання тестів на різних етапах навчання. Запропоновано базовий алгоритм складання комп'ютерного тесту. Наведено приклади можливих технічних рішень.

Ключові слова: контроль; тест; переваги; рівні засвоєння; алгоритм; тестова оболонка.

Jim. 9.

Yuliya Kornytska, Ph.D.(Pedagogy), Associate Professor National Technical University of Ukraine "Kyiv Ihor Sikorskiy Polytechnic Institute"

\section{THE ROLE AND PLACE OFTESTING IN THE FOREIGN LANGUAGE TEACHING PROCESS}

The paper is devoted to the analysis of the testing methods implementation in the process of developing foreign language competence. Nowadays, the foreign language is considered as a means of communication and an effective tool for advancement both personal and professional. In conditions of the education paradigm shift, the methodology of foreign language teaching experiences a variety of innovations aimed to bring it in accordance to the new framework. Improving the process of developing foreign language competence actualizes the questions of its quality control as a significant condition for its success. The peculiarities of the new curricula impose to use more flexible, rational and technological methods of assessment. On the basis of the theoretical analysis of the actual researches, the author outlines testing as the most appropriate one to provide efficient, impartial and systematic monitoring and assessment. Computer-aided testing is considered as the solution for enhancing above mentioned pros and making the process more technological with concomitant advantages. The paper presents the key advantages of testing in comparison to the traditional methods, benefits of computeraided testing. The author reasons the practicability of implementing test on the different stages of the acquiring process. Based on the results of actual researches and practical experience, the algorithm of developing computer test is described and some available technical solutions are offered with the detailed description of the one used by the author in practice. As the perspective vector for further investigation on the problem the author outlines stating and specifying pedagogical conditions for implementing computer-aided testing.

Keywords: a control; a test; advantages; an acquisition level; an algorithm; the test frame.

П остановка проблеми. Компетентністна парадигма сучасної вищої освіти актуалізує пошук нових рішень в методиці викладання іноземних мов. Однак, для забезпечення належної якості іншомовної підготовки важливим є не лише вдосконалення процесу розвитку іншомовної комунікативної компетентності, але й пошук адекватних форм його моніторингу. Своєчасна та об'єктивна інформація про хід навчального процесу,

(C) Ю. Корницька, 2018 проблемах та досягненнях студентів у оволодінні іншомовною комунікативною компетенцією $є$ необхідною умовою ефективного навчального процесу. Зважаючи на протиріччя між існуючими вимогами та обмеженою кількістю аудиторних годин особливої актуальності набуває пошук шляхів та способів оптимізації процесу навчання іноземних мов та використання нових гнучких, раціональних і технологічних методів контролю та самоконтролю. Оптимальним рішенням для 
забезпечення економії та раціонального розподілу навчального часу, об'єктивності та систематичності моніторингу навчального процесу, виконання ретельного аналізу та виявлення проблем 3 метою своєчасного коригування дослідники вважають тестування.

Аналіз актуальних досліджень. Теоретичною основою нашого дослідження стали роботи присвячені: питанням педагогічного моніторингу, діагностики процесу та результату навчання, визначення ролі та місця тестування в навчальному процесі (В.С. Аванесов, Ю.К. Бабанський, Л.А. Громакова, Т.С. Клімова, Д.Ш. Матрос, Ю.М. Нейман, О.І. Павлюченко, В.О. Хлєбніков та ін.); аспектам розробки та використання тестів для оцінки якості навчання (I.Є. Булах, В.А. Кокота, Н.М. Дюканова, В.І. Звонніков, Т.О. Кабанова, Н.Л. Майорова, О.М. Радьков, Н.Ф. Тализіна, М.Б. Челишкова та ін.); специфіці комп'ютерного тестування (Т.Ю. Горова, Т.Д. Дегтярьова, О.В. Кузнєцова, С.С. Копилова, Д.Ш. Матрос, В.П. Овчаренко, І.Ю. Павловська, А.О. Татур, О.Г. Шмельов, Н.В. Ялаєва та ін.).

Мета дослідження. Здійснити теоретичний аналіз і обгрунтування доцільності використання тесту як важливої складової сучасної системи контролю в навчальному процесі внз. Представити алгоритм розробки комп'ютерного тесту та технічні можливості для його реалізації.

Виклад основного матеріалу. Сучасні вимоги до якості іншомовної підготовки майбутнього фахівця технічного профілю передбачають використання нових розвиваючих педагогічних технологій, що базуються на активних та рефлексивно-діяльнісних формах та методах навчання та створюють сприятливі умови для формування стійкої системи знань, розвитку у студентів вмінь самостійної навчальної діяльності та здатності переносити отримані знання і вміння на реальні ситуації професійного та соціального життя $[5,31]$. Однак, незважаючи на існуючий досвід в даному напрямку, проблема належної діагностики процесу та розробки відповідного інструментарію на сьогоднішній день все ще $\epsilon$ актуальною.

Методика контролю та оцінки знань має відповідати цілям, змісту та методам навчання. В педагогічній практиці на сьогоднішній день домінуючими залишаються традиційні методи: опитування (усні та письмові), контрольні та самостійні роботи, іспити. До нових методів контролю, що є більш адекватними актуальним технологіям навчання відносять метод проектів, ділову гру, кейс-метод та ін. Їх ключовою відмінністю $є$ оцінювання не лише кінцевого результату, але й діяльності студента в процесі його досягнення

Незважаючи на широкий вибір методів контролю (як нових так і традиційних) виділяють наступні проблеми якості діагностики знань: об'єктивність (особливо при усних опитуваннях); об'єм матеріалу, що підлягає перевірці; економічність (час та кошти); ефективність [1].

Для подолання означених проблем дослідники пропонують використовувати потенціал педагогічних тестів. Тестування відрізняється від інших методів оцінки пред'явленням чітко визначених вимог до процесу, матеріалів, методів їх обробки та інтерпретації результатів. До переваг використання тестів в навчальному процесі відносять:

- об'єктивність, що виключає суб'єктивні оціночні судження й висновки викладача;

- систематичність, тобто, можливість детальної перевірки рівня засвоєння кожного змістового модуля дисципліни;

- можливість економії аудиторного часу;

- більша точність кваліфікації помилок в письмових роботах, що, в свою чергу, розвиває вплив цього виду оцінки знань на логічне мислення та спрямованість студентів на більшу точність у відповідях;

- індивідуальний характер контролю, можливість здійснення контролю як прогресу окремого студента так всієї групи, що допоможе оцінити викладачеві ефективність методів та прийомів, які застосовуються;

- можливість чітко визначити причини недостатнього засвоєння матеріалу та достовірність результатів;

- розгорнута рейтингова система оцінки результатів тестування надає процесу об'єктивності, технологічності та підвищує його ефективність;

- можливість застосування як засобу усіх видів контролю: базового, початкового, поточного, тематичного, рубіжного, залікового, підсумкового та екзаменаційного, а також самоконтролю [3 $5 ; 8]$.

Безперечно, тести мають і недоліки та обмеження, які необхідно враховувати при використанні цього методу. Дослідники, відзначаючи потенціал тестування, водночас наголошують на раціональності використання методу - тести покликані не замінити, а гармонійно доповнити інші методи діагностики для отримання максимально якісного результату $[1 ; 5,92]$. Наприклад, ефективне використання активних та інтерактивних форм навчання можливе лише на етапі накопичення студентами 
певного об'єму знань. Для виявлення цього об'єму доцільно використовувати тести, оскільки така форма контролю дозволить отримати найбільш повну інформацію $з$ мінімальною витратою навчального часу [6, 67].

В практиці вищої школи загальновживаним та доцільним підходом до оцінювання якості навчання є рівнева модель засвоєння знань В.П. Беспалько [2]. Аналіз моделі дозволяє виявити поступове зниження потенційної ефективності тестів від першого до найвищого рівня. Раціональний вибір форми контролю зумовлюється його цілями, змістом навчального матеріалу, особливостями дисципліни тощо. Розглянемо більш детально співвідношення рівнів моделі та форм і типів контрольних завдань, що максимально відповідають знанням та вмінням на кожному $з$ них.

На першому рівні (знання-знайомства) відбувається ідентифікація при повторному сприйнятті попередньо отриманої інформації. Для цього рівня доцільним буде використання контрольних завдань спрямованих на виділення вивченого об' єкту серед ряду інших. Вибір форми контрольного завдання може бути довільним. Раціональним та доцільним є використання тестів закритого типу (альтернативний вибір, встановлення відповідності, множинний вибір тощо).

На другому рівні (знання-копії) відбувається репродукція отриманих знань шляхом самостійного механічного відтворення i усвідомленого застосування інформації в типових ситуаціях. Доцільним $є$ використання типових задач (ситуацій), тестових завдань закритого (встановлення послідовностей, множинний вибір, встановлення відповідності) і відкритого типу (доповнення).

На третьому рівні (знання-вміння) передбачається продуктивна дія студента, тобто, студент здатен самостійно відтворювати та трансформувати засвоєну інформацію для обговорення відомих об'єктів та застосування іiі в різних нетипових ситуаціях. При цьому, студент здатен генерувати суб'єктивно нову інформацію про вивчені об'єкти та дії з ними. Доцільним є використання нетипових задач (реальних ситуацій), проблемних завдань та тестів відкритого типу (вільний виклад).

Найвищій четвертий рівень (творча діяльність) передбачає продуктивну діяльність студента та здатність генерувати об'єктивно нову інформацію. Доцільним є використання методу науково-дослідницьких проектів [2].

Отже, для виявлення евристичних та творчих вмінь доцільно використовувати проблемні, нетипові завдання або проекти, в той час як на перших двох рівнях використання тестів раціональним та ефективним варіантом організації контролю. Раціональне та обгрунтоване використання тестів допомагає:

- студенту впевнено орієнтуватися в навчальному матеріалі, отримувати об'єктивне уявлення про власний прогрес, своєчасно усувати недоліки та прогалини в підготовці;

- викладачеві раціонально використовувати навчальний час, оцінювати ефективність методів та прийомів викладання, отримувати повну та достовірну картину прогресу та чітко визначати причини недостатнього засвоєння матеріалу студентами $[4,145 ; 6,91]$.

Активна інформатизація та комп'ютеризація навчального процесу в сучасному ВНЗ сприяє популяризації комп'ютерного тесту як інструменту для забезпечення ще більшої оперативності та динамічності цієї діагностичної процедури. Дослідники відзначають наступні переваги комп'ютерного тестування:

1. Економія часового ресурсу та зменшення навантаження на викладача.

2. Об'єктивність - виключений фактор суб'єктивного підходу та стороннього впливу, i, як наслідок, позитивний стимулюючий вплив на пізнавальну діяльність студента.

3. Валідність - виключено фактор “лотереї” оскільки більша кількість завдань тесту охоплює весь об'єм матеріалу, що надає студенту можливість продемонструвати повний діапазон знань $з$ теми.

4. Простота - тестові запитання більш конкретні та лаконічні.

5. Демократичність - всі студенти знаходяться в рівних умовах, результати тестування прозорі та часто представляються у формі аналізу 3 виведенням типових помилок та відсоткового співвідношення.

6. Масовість та оперативність - можливість за певних проміжок часу охопити контролем більшу кількість студентів, що економить навчальний час відведений на перевірку знань (до 50 \%) який можна використати більш ефективно та раціонально.

7. Технологічність - базується на можливості автоматичної обробки.

8. Достовірність інформації про об'єм засвоєного матеріалу та рівні його засвоєння.

9. Надійність - тестова оцінка однозначна (оскільки автоматична обробка результатів майже виключає можливість помилки) та відтворювана (результати тривалий час зберігаються в базі даних). 
10. Можливість відстежувати динаміку прогресу як кожного студента окремо так і групи в цілому завдяки аналізу результатів, що зберігаються в банку даних та доступні для перегляду та співставлення.

11. Диференціююча здатність - за рахунок наявності завдань різного рівня складності.

12. Реалізація індивідуального підходу в навчанні, можлива індивідуальна перевірка та самоперевірка.

13. Можливість застосування мультимедійних технологій, що пропонують текстову, графічні, анімаційні та відеоматеріали в найбільш ефективних поєднаннях i таким чином активізують одночасно всі канали сприйняття інформації. Коректність відповіді також може буги представлена графічно.

14. Психологічний комфорт студентів під час тестування [3; $5-7]$.

Однак, науковці відзначають, що переваги комп'ютерного тестування очевидні лише за умови грамотного та компетентно складеного тесту в його основі [4; 8]. Розробка якісного тесту процес складний та трудомісткий. Грунтовний аналіз актуальних досліджень та практичного досвіду уможливив складення базового алгоритму цього процесу, що є послідовністю наступних етапів:

1) визначення мети та формалізація моделі знань;

2) формування завдань;

3) формування тесту;

4) апробація та корекція.

Розглянемо їх більш детально.

Перший етап передбачає чітке визначення мети контрольного заходу та проектування моделі. За метою використання тести поділяють на навчальні (для самостійного опрацювання теми, повторення або закріплення матеріалу), діагностичні (для виявлення прогалин в знаннях, уміннях, навичках студентів 3 наступним аналізом спрямованим на усунення виявлених проблем) і контрольні (для діагностики рівня засвоєння, перевірки знань та вмінь здобутих та вироблених в результаті опрацювання теми, розділу тощо) [4 - 6]. Побудова моделі знань передбачає формалізацію матеріалу який підлягає перевірці. Існує два типи побудови моделі - спадна та висхідна. Спадна модель передбачає поділ загального змісту теми на модулі (розділи) які, в свою чергу, деталізуються на підмодулі (підрозділи). Висхідна модель передбачає роботу в зворотному напрямку - від простого до складного. Всі елементи системи мають бути взаємопов'язаними в загальній структурі [3; 8]. Наприклад, для створення контрольного тесту спрямованого на визначення рівня засвоєння граматичної теми “Present Tenses” (Теперішні часи - англійська мова) ми застосували спадну модель проектування за якою тему було поділено на чотири модулі: "Present Simple", "Present Continuous", "Present Perfect", "Present Perfect Continuous", кожен з яких було деталізовано на підмодулі: “affirmative”, "negative”, “question”. Результат цього етапу доцільно оформити у вигляді узагальненої схеми, що спростить процес подальшого аналізу та корегування.

Етап формування завдань передбачає добір форм тестових завдань та їх наповнення. Вибір форми завдань зумовлюється специфікою змісту дисципліни, метою створення та застосування тесту. Відбір та структура завдань тесту залежить від того, які навички та показники необхідно перевірити. Формулювання завдань має відповідати основним вимогам залежно від форми та типу [4, 129]. Наприклад, при формулюванні завдань для перевірки граматичної теми в тесті закритої форми з завданнями множинного вибору ми: уникали штучного ускладнення речень умови; обирали однорідні та правдоподібні дистрактори, при формулюванні яких використовували поширені та типові помилки; пропонували 4 - 5 варіантів відповідей. На цьому етапі доцільно оформити план тесту, наприклад у вигляді таблиці в якій кожне тестове завдання буде співвіднесено 3 певним елементом моделі знань та конкретним видом знань та вмінь, що спростить процес подальшого аналізу, оцінки та коригування.

Для автоматизації процесу тестування на етапі формування тесту використовується комп'ютер та спеціальне програмне забезпечення. Оскільки ефективність тестування 3 допомогою комп'ютерних систем напряму залежить від середовища у якому розробляється тест та проводиться тестування актуальною $є$ проблема вибору програмного забезпечення [7, 52]. На сьогоднішній день існує достатня кількість тестових оболонок різного типу: безкоштовні, умовно безкоштовні та комерційні. Найбільшим функціоналом характеризуються саме комерційні оболонки. До переваг комерційних систем відносять: стабільну технічну підтримку; додаткові функціональні можливості; оригінальний дизайн; регулярне централізоване оновлення систем, підтримку програмного забезпечення. Однак, за умов обмеженого фінансування варто звернути увагу на програми Test-W, Open TEST, RichTest, Knowing, MyTest вартість яких є невисокою, та системи, що дозволено використовувати на пільгових умовах навчальним закладам, 
наприклад INDIGO. Оскільки програмне забезпечення з інтерфейсом має бути державною мовою або мовою, якою ведеться навчальний процес, важливим критерієм є можливості локалізації. Українську та англійську мови можна обрати у налаштуваннях EasyQuizzy, Hot Potatoes, SunRav TestOfficePro, MyTest, OpenTEST, INDIGO, RichTest.

На основі аналізу функціональних можливостей та доступності для використання у власній практичній діяльності ми обрали тестову оболонку - UniTest System, що відноситься до категорії умовно безкоштовних. Пакет програм UniTest System це середовище для створення тестів та проведення тестування (як локально, так i в загальній мережі), що пропонує функцію детального аналізу результатів та складання звітів.

Основні функціональні можливості UniTest System:

1. Високий рівень адміністрування та безпеки: обов'язкова реєстрація користувачів 3 можливістю тимчасового блокування; моніторинг підключених користувачів в реальному часі та доступ до інформації про проходження тесту студентом (обрана відповідь, витрачений час на відповідь, вірність цієї відповіді тощо); можливість створення звітів за результатами тестувань у індивідуальному форматі або з використанням шаблонів; можливість організації вибірки та сортування результатів.

2. Простота використання: дружній інтерфейс та можливість задавати індивідуальні налаштування; підтримка англійської, німецької, французької та іспанської мов; власний простий редактор для створення тестів.

3. Інструменти формування: підтримка основних форм та типів - прості запитання, запитання множинного вибору (до 20 варіантів відповідей), упорядкування послідовностей, встановлення відповідності, пряме введення тощо; можливість включення до тесту завдань 3 OLE-об'єктами (документи, графіка тощо) включаючи інтерактивні (анімація, відео та аудіо); можливість налаштування індивідуального шкалування (від 1 до 5) для кожного завдання тесту; можливість перемішування завдань та варіантів відповідей випадковим чином; можливість створення загальної бази даних завдань та їх розподілу за рівнем складності 3 функцією довільного вибору та автоматичного формування нових тестів [9].

Для отримання достовірних та об'єктивних характеристик тестових завдань та тесту в цілому необхідно проведення апробації, яка включає наступні етапи: 1) проведення тестування в репрезентативній групі що включає розробку інструкції, пред'явлення тесту та отримання результатів; 2) статистична обробка результатів, їх аналіз з метою отримання характеристики завдань та тесту в цілому; 3) первинна корекція $[7,74]$. В процесі подальшого використання тести також підлягають корекції та вдосконаленню для досягнення максимальної валідності.

Висновки та перспективи подальшого дослідження. Таким чином, тестування, за умов доцільного та рацінального застосування, має значний потенціал для забезпечення якості та оптимізації навчального процесу. Використання компютерних тестів надає можливість систематичного об'єктивного моніторингу динаміки становлення іншомовної комунікативної компетентності та своєчасної корекції проблем. Подальшого дослідження потребують психологопедагогічні умови використання комп'ютерних тестів в навчальному процесі технічного внз.

\section{ЛІТЕРАТУРА}

1. Аванесов В. С. Материалы публикаций в открытых источниках [Електронний ресурс] / В. С. Аванесов // МКО УГТУ-УПИ. - 2005. - Режим доступу до ресурсу: http:/www.charko.narod.ru/tekst/ biblio/Avanesov_Teoriya_i_metod_ped_izmer.pdf.

2. Беспалько В. П. Педагогика и прогрессивные технологии обучения / В. П. Беспалько. - М.: ИРПО MO, 1995. - $336 \mathrm{c}$.

3. Булах I. Є. Створюємо якісний тест / I. С. Булах, М. Р. Мруга. - К.: Майстер-клас, 2006. - 160 с.

4. Ефремова Н. Ф. Тестовый контроль в образовании / Н. Ф. Ефремова. - М.: Логос, 2007. - 368 с.

5. Майорова Н. Л. Тестирование как педагогическое средство измерения успешности обучения: дис. канд. пед. наук: 13.00.01 / Майорова Наталия Львовна Ярославль, 2000. - 216 с.

6. Турикова Е. А. Лингводидактическое тестирование как средство обучающего контроля уровня сформированности общеучебных и профессиональных компетенций студентов-нефилологов: дис. канд. пед. наук: 13.00.02 / Турикова Елизавета Александровна Москва, 2016. - 200 с.

7. Фетісов В. С. Комп'ютерні технології в тестуванні / В. С. Фетісов. - Ніжин: Видавець ПП Лисенко М.М., 2011. - 140 с.

8. Челышкова М. Б. Теория ипрактика конструирования педагогических тестов / М. Б. Челышкова. - М: Логос, 2002. -432 c.

9. http://www.softportal.com/software-1131-unitestsystem.html

\section{REFERENCES}

1. Avanesov, V. S. (2005). Materialyi publikatsiy v otkryityih istochnikah [Materials of open sours publications]. MKO UGTU-UPI. Available at: $\mathrm{charko.narod} . \mathrm{ru} / \mathrm{t}$ e k s t/b i b $1 \mathrm{io/}$ Avanesov_Teoriya_i_metod_ped_izmer.pdf. [in Russian]. 


\section{МОДЕЛЮВАННЯ ПРОЦЕСУ ВИХОВАННЯ ДУХОВНО-МОРАЛЬНИХ ЦІННОСТЕЙ У СТУДЕНТІВ ГУМАНІТАРНИХ СПЕЦІАЛЬНОСТЕЙ ЗАСОБАМИ ХУДОЖНЬОЇ ЛІТЕРАТУРИ}

2. Bespalko, V. P. (1995). Pedagogika i progressivnyie tehnologii obucheniya [Pedagogy and progressive technologies of teaching]. Moscow.: IRPO MO, $336 \mathrm{p}$. [in Russian].

3. Bulah, I. E. (2006). Stvoryuemo yakisniy test [Creating a qualitative test]. Kyiv: Mayster-klas, 160 p. [in Ukrainian].

4. Efremova, N. F. (2007). Testovyiy kontrol v obrazovanii [Test control in education]. Moscow: Logos, 368 p. [in Russian].

5. Mayorova, N. L. (2000). Testirovanie kak pedagogicheskoe sredstvo izmereniya uspeshnosti obucheniya [Testing as a pedagogical means of the learning success measuring]. Candidate's thesis. Yaroslavl, 216 p. [in Russian].

6. Turikova, E. A. (2016). Lingvodidakticheskoe testirovanie kak sredstvo obuchayuschego kontrolya urovnya sformirovannosti obscheuchebnyih i professionalnyih kompetentsiy studentov-nefilologov [Linguodidactical testing as a means of training control for the general educational and professional competences formation level of non-philological students]. Candidate's thesis. Moscow, $200 \mathrm{p}$. [in Russian].

7. Fetisov, V. S. (2011). Kompyuterni tehnologiyi v testuvanni [Computer technology in testing]. Nizhin: Lisenko M.M. Publ., 140 p. [in Ukrainian].

8. Chelyishkova, M. B. (2002). Teoriya i praktika konstruirovaniya pedagogicheskih testov [Theory and practice of developing pedagogical tests]. Moscow: Logos, 432 p. [in Russian].

9. Available at: http://www.softportal.com/software1131-unitest-system.html [in Russian].

Стаття надійшла до редакції 02.03.2018

УДК [378.015.31:17.022.1]:821

DOI:

Сергій Гуров, кандидат педагогічних наук, доиент кафедри англійської філологї̈ та методики викладання англійської мови Мелітопольського державного педагогічного університету імені Богдана Хмельницького

\section{МОДЕЛЮВАННЯПРОЦЕСУ ВИХОВАННЯДУХОВНО-МОРАЛЬНИХЦННОСТЕЙ УСТУДЕНТІВГУМАНТТАРНИХСПЕЦАЛЬНОСТЕЙЗАСОБАМИХУДОЖНЬОЇЛТТЕРАТУРИ}

У статті представлено теоретико-концептуальну модель виховання духовно-моральних ияінностей студентів гуманітарних спеціальностей засобами художньої літератури, проведено аналіз теоретичних працьв вітчизняних та зарубіжних науковців, який свідчить, щчо необхідність педагогічного моделювання зумовлена потребою в об' єднанні всіх знань про особистість, в якої необхідно виховати духовно-моральні иінності засобами художньої літератури. Ефективне виховання духовних і моральних иінностей студентів гуманітарних наук можливе за умови створення теоретично обгрунтованої та експериментально підтвердженої теоретико-кониептуальної моделі.

Ключові слова: духовно-моральні ияінності; студенти гуманітарних спеціальностей; теоретикоконцептуальна педагогічна модель.

תim. 6.

Serhiy Hurov, Ph.D.(Pedagogy), Associate Professor of the English Philology and Methods of Teaching English Department Melitopol Bohdan Khmelnytskiy State Pedagogical University

\section{MODELING THE PROCESS OF EDUCATION OF SPIRITUAL-MORAL VALUES AMONG STUDENTS OF HUMANITARIAN SPECIALTIES BY MEANS OF IMAGINATIVE LITERATURE}

The article deals with a theoretical and conceptual model of spiritual and moral values development of students of humanitarian specialties by means of imaginative literature, the analysis of theoretical works of scientists indicates that the necessity of pedagogical modeling is determined by the needs to combine all the knowledge about the personality. Thus, due to this model it becomes possible to educate spiritual and moral values by means of imaginative literature. The article also discovers effective education of the spiritual and moral values of students of humanities is possible provided that a theoretically grounded and experimentally verified theoretical-conceptual model is created. The article visualizes the theoretical and conceptual model of the process of raising the spiritual and moral values of students of humanitarian specialties by means of imaginative literature, as a descriptive analogue of the result, which reproduces the peculiarities of the pedagogical reality of higher educational institutions.

The components can be implemented due to a certain order in the technological process components of the model. Since the upbringing of spiritual and moral values is being investigated in the context of vocational training, the proposed model represents the integration of all the above components. At the same time, in this 